\title{
Usability Evaluation of Comprehension Performance and Subjective Assessment on Mobile Text Advertising
}

\author{
Ya-Li Lin and Chih-Hsiang Lai \\ Department of Statistics, Tunghai University, \\ 40704 Taichung, Taiwan \\ \{Ya-Li.Lin, Chih-Hsiang.Lai, yllin\}@thu.edu.tw
}

\begin{abstract}
The effects of text presentation applied to mobile advertisings were examined in the context of the explosion of small-screen devices. Presentation mode of text advertising visual structure, position of layout, moving speed, format of segmented presentation, and luminance contrast of text/background window are used as design factors. Ad comprehension, user interface satisfaction, and overall workload would be collected using an orthogonal array experiment. The results indicate the interaction effects of presentation mode and position as well as presentation mode and speed on Ad comprehension are statistically significant. In addition, the interaction effects of presentation mode and format as well as presentation mode and position are statistically significant on user interface satisfaction. It also indicates the interaction effects of presentation mode and format as well as presentation mode and luminous contrast are statistically significant on overall workload. In summary, the interaction effects between text advertising visual structures have to be taken into account for the user-centered usability of mobile text advertising presentation.
\end{abstract}

Keywords: Mobile Text Advertising, NASA-TLX, Leading Display, User Interface Satisfaction (UIS), Rapid Serial Visual Presentation (RSVP).

\section{Introduction}

In recent years, electronic commerce is getting to expand towards mobile commerce. Mobile advertising is a rapidly growing sector providing brands, agencies and marketers the opportunity to connect with consumers beyond traditional and digital media and directly on their mobile phones [24]. It is a form of advertising via mobile (wireless) phones or other mobile devices. As the internet is reinvented on mobile devices - smaller, more personal and personalized, ubiquitously accessible - established forms of interactive advertising will also evolve as they migrate from PCs to mobile devices.

Mobile Advertising refers to advertising or marketing messages delivered to mobile devices, either via a synchronized download or wirelessly over the air [14]. Although this broad definition potentially included advertisings delivered to laptops, media players, and other classes of mobile device, in practice the most interesting and potentially 
revolutionary part of the mobile advertising market line in delivering messages to nonPC devices - primarily mobile phones, but also including mobile devices.

Mobile interactivity is in some ways similar to the PC-based internet, and these similarities will speed advertisers' ability to take advantage of the mobile medium. The key findings in Lin and Chen focused on the click-through rate for the advertising effectiveness to examine the effects of design factors on animated online advertisings [7]. Their findings showed order effect, two-factor interaction effect of ad types and presentation positions, as well as presentation position and animation lengths are $\mathrm{s}$ tatistically significant. In addition, the report of IAB indicated that text-based advertising remains the most common creative format on both the web and other applications like short message services (SMS) [2,3]. Mobile Marketing Association (MMA) has published mobile advertising guidelines, but it is difficult to keep such guidelines current in such a fast-developing area [8]. Leveraging accepted Web advertising best practice will facilitate building a successful mobile advertising business. At the same time, the user experience, interactivity, and expectations of consumers on the mobile web differ from their PC counterparts, and simply transplanting PC-optimized advertising onto mobile device is unlikely to yield optimal results.

As small screen interfaces become more and more popular, especially mobile display advertising, an important usability problem is how best to display mobile text advertising on small screen. One possibility is to use dynamic presentation methods involving the movement of text on the screen. These methods have been shown to be viable alternatives for displaying text information on small screen of non-PC devices or limited screen space of PC-based devices [4-6, 9-10]. These studies focused on investigating users' visual performance, readability, and reading comprehension of dynamic or continuous texts. However, it lacks of providing the guideline of the user experience, interactivity, and expectations of consumers on the mobile web, including the current trends in advertising as delivered to mobile phones. The objective of this study is to evaluate the reading comprehension performance of mobile text advertising using static and dynamic moving display on the interface of mobile phone. The usability evaluation is used to achieve specified goals with efficiency, preference, and user interface satisfaction.

\section{Methods}

\subsection{Participants}

Twenty-seven undergraduate and graduate students (13 females and 14 males) from Tunghai University participated individually in the experiment.

\subsection{Materials}

Macromedia Flash CS3 and SWiSHzone SWiSHmax are used to design the simulated mobile text advertising interface. The simulated interface contained search results and visual structure of text advertising. The size of mobile text advertising is categorized 
as large image banner $(216 \times 36$ pixels $)$ in accordance to MMA guidelines [8]. Mobile advertising of one line of text up to 18 Chinese words is adopted. The font was "New Thin Ming Ti”, font size was 12 points. In addition, CyberLink StreamAuthor 3.0 is used to record the process of screen operation during the experiment. A digital video camera recorder (SONY DCR-PC330) is used to record the overall process of experiments and after-experiment questionnaire. In addition, the luminance of experimental lab is 487 611 lux measured by Lutron LX-101 Lux meter.

\subsection{Experimental Design}

A design of $\boldsymbol{L}_{27}\left(3^{13}\right)$ orthogonal array experiment is used to collect the comprehension performance. A questionnaire for user interface satisfaction (QUIS) and National Aeronautics and Space Administration Task Load Index (NASA-TLX) task load index [1] will be implemented and analyzed after the experiment. Five design factors are: (1) presentation mode (M) --Rapid Serial Visual Presentation (RSVP), Leading, and Static, (2) presentation position (P)--Top, Bottom, End-of-Search position, (3) presentation speed (S)--80, 170, and 260WPM, (4) format (F)--keyword-by-keyword, phrase-by-phrase, and sentence), and (5) luminance contrast (C)--2/3, 4/5, and 8/9 for mobile text advertisings would be investigated. There are two-hundred forty-three treatment combinations for the five design factors and each factor has 3 levels. Based on $L_{27}$ orthogonal array design, one-ninth of complete factorial design, that is, twenty-seven treatment combinations will be implemented. One of twenty-seven treatment combinations is randomly assigned to a participant.

\subsection{Procedure}

The experiment session lasted roughly one and half hours. Firstly, participants read instructions displayed on the computer screen. Participants were informed that they had to read the search results and mobile text ads in order to perform a reading comprehension test. A predesigned simulated system including search results and text ad is shown within 30 seconds. Participants were asked to answer five propositions based on the contents of searching results and associated mobile text advertising for previous pages. Twenty search topics are randomly assigned in the experiment. Fill in QUIS and NASA-TLX after completing the reading comprehension test.

\section{$3 \quad$ Results}

\subsection{Comprehension Performance}

Reading comprehension score (RCS) is the number of propositions correctly answered in a given time limit (total=100). Summary statistics of reading comprehension score is shown in Table 1. It indicates Leading Mode has the best reading comprehension (mean of $\mathrm{RCS}=96.0, \mathrm{SD}=4.6$ ), Bottom position has the best reading 
comprehension (mean of $\mathrm{RCS}=97.7, \mathrm{SD}=1.3$ ), Presentation speed of 170WPM has the best reading comprehension (mean of $\mathrm{RCS}=96.3, \mathrm{SD}=4.2$ ), Keyword-by-Keyword format has the best reading comprehension (mean of RCS=95.8, SD=3.2), and Luminance contrast of $4 / 5$ has the best reading comprehension (mean of $\mathrm{RCS}=96.1$, $\mathrm{SD}=3.3$ ). Since reality must be reduced to manageable proportions whenever we construct models, only a limited number of factors and their interactions should be included in a regression model. Some evidence of the internal validity of these fitted models can be obtained through an examination of the various model-selection criteria. Table 2 summarizes the fits of the five candidate models. As a consequence of the concerns, Model (3) and Model (5) were eliminated from the consideration of normality about model assumptions. While Models (1), (2), and (4) performed comparably in the $\mathrm{R}^{2}, \mathrm{R}_{\text {Adj }}$, and Akaike's information criterion (AIC), Models (2) and (4) performs better than Model (1) in $\mathrm{R}^{2}, \mathrm{R}_{\mathrm{Adj}}^{2}$, and AIC. The final selection was based on the principle of parsimony, Model (2) achieves this level of performance with one fewer parameter than Model (4). For this reason, Model (2) is ultimately chosen as the final model. The fitted regression model of RCS is expressed in Equation (1) as following:

$$
\begin{aligned}
& \hat{\mu}=89.96+0.33 \mathrm{M}_{1}+3.56 \mathrm{M}_{2}+6.33 \mathrm{P}_{1}+6.67 \mathrm{P}_{2}-3 \mathrm{~S}_{1}-4.67 \mathrm{~S}_{2} \\
& +1.78 \mathrm{C}_{1}+2.33 \mathrm{C}_{2}-0.67 \mathrm{M}_{1} \times \mathrm{P}_{1}-1.33 \mathrm{M}_{1} \times \mathrm{P}_{2}-1.33 \mathrm{M}_{2} \times \mathrm{P}_{1} \\
& -7.33 \mathrm{M}_{2} \times \mathrm{P}_{2}+7 \mathrm{M}_{1} \times \mathrm{S}_{1}+2.67 \mathrm{M}_{1} \times \mathrm{S}_{2}
\end{aligned}
$$

where:

$$
\begin{aligned}
& \mathrm{M}_{1}=\left\{\begin{array}{l}
1, \text { if Leading } \\
0, \text { otherwise }
\end{array}, \mathrm{M}_{2}=\left\{\begin{array}{l}
1, \text { if RSVP } \\
0, \text { otherwise }
\end{array}\right.\right. \\
& \mathrm{P}_{1}=\left\{\begin{array}{l}
1, \text { if Bottom } \\
0, \text { otherwise }
\end{array}, \mathrm{P}_{2}=\left\{\begin{array}{l}
1, \text { if } \text { End }- \text { of }- \text { search } \\
0, \text { otherwise }
\end{array}\right.\right. \\
& \mathrm{S}_{1}=\left\{\begin{array}{l}
1, \text { if } 170 \mathrm{WPM} \\
0, \text { otherwise }
\end{array}, \mathrm{S}_{2}=\left\{\begin{array}{l}
1, \text { if } 260 \mathrm{WPM} \\
0, \text { otherwise }
\end{array}\right.\right. \\
& \mathrm{F}_{1}=\left\{\begin{array}{l}
1, \text { if Keyword } \\
0, \text { otherwise }
\end{array}, \mathrm{F}_{2}=\left\{\begin{array}{l}
1, \text { if Phrase } \\
0, \text { otherwise }
\end{array}\right.\right. \\
& \mathrm{C}_{1}=\left\{\begin{array}{l}
1, \text { if LC }=2 / 3 \\
0, \text { otherwise }
\end{array}, \mathrm{C}_{2}=\left\{\begin{array}{l}
1, \text { if } \text { LC }=4 / 5 \\
0, \text { otherwise }
\end{array}\right.\right.
\end{aligned}
$$

To understand the meaning of the regression coefficients, $\mathrm{M} 1=1$ and $\mathrm{M} 2=0$ would be substituted for the presentation of Leading mode in Equation (1), M1=0 and M2=1 for RSVP mode, and M1=0 and M2=0 for Static mode. Similarly, P1=1 and P2=0 would be substituted for the presentation of Bottom position in Equation (1), P1=0 and $\mathrm{P} 2=1$ for End-of-Search position, and $\mathrm{P} 1=0$ and $\mathrm{P} 2=0$ for Top position; $\mathrm{S} 1=1$ and $\mathrm{S} 2=0$ would be substituted for the speed of $170 \mathrm{WPM}, \mathrm{S} 1=0$ and $\mathrm{S} 2=1$ for $260 \mathrm{WPM}$, and $\mathrm{S} 1=0$ and $\mathrm{S} 2=0$ for $80 \mathrm{WPM} ; \mathrm{F} 1=1$ and $\mathrm{F} 2=0$ would be substituted for the presentation format of keyword-by-keyword, F1=0 and F2=1 for phrase-by-phrase, and $\mathrm{F} 1=0$ and $\mathrm{F} 2=0$ for sentence-by-sentence; $\mathrm{C} 1=1$ and $\mathrm{C} 2=0$ would be substituted for the luminance contrast of $2 / 3, C 1=0$ and $C 2=1$ for $4 / 5$, and $C 1=0$ and $C 2=0$ for $8 / 9$.

In Table 3, the results indicate the interaction effects of presentation mode and position as well as presentation mode and speed on Ad comprehension are statistically 
significant. Interaction plot of presentation mode and position $(\mathrm{M} \times \mathrm{P})$ is illustrated in Fig. 1(a). It indicates that mobile text ad of the Bottom position outperforms than ones of the Top position for all the three presentation modes. The combination of RSVP mode and End-of-Search position has the worst reading comprehension performance. There is only little difference between Leading and static modes on reading comprehension performance. In addition, interaction plot of presentation mode and speed $(\mathrm{M} \times \mathrm{S})$ is illustrated in Fig. 1(b). It indicates that the combination of Leading mode and 170 WPM has the best reading comprehension performance, however, the combination of RSVP mode and 260 WPM has the worst reading comprehension performance.

Table 1. Summary statistics of reading comprehension score (RCS)

\begin{tabular}{|c|c|c|c|c|c|c|c|c|c|}
\hline Factor & Level & $\mathrm{n}$ & Mean & SD & Min & $\mathbf{Q}_{1}$ & $\mathbf{Q}_{2}$ & $\mathbf{Q}_{3}$ & Max \\
\hline \multirow{3}{*}{ Mode } & RSVP & 9 & 93.8 & 4.0 & 88 & 90 & 96 & 97 & 98 \\
\hline & Leading & 9 & 96.0 & 4.6 & 85 & 96 & 97 & 99 & 100 \\
\hline & Static & 9 & 95.7 & 3.6 & 90 & 93 & 97 & 97 & 100 \\
\hline \multirow{3}{*}{ Position } & Top & 9 & 92.0 & 4.3 & 85 & 90 & 92 & 93 & 99 \\
\hline & Bottom & 9 & 97.7 & 1.3 & 96 & 97 & 98 & 98 & 100 \\
\hline & End-of-Search & 9 & 95.8 & 3.9 & 89 & 96 & 97 & 97 & 100 \\
\hline \multirow{3}{*}{ Speed } & 80WPM & 6 & 95.8 & 1.5 & 93 & 96 & 96 & 97 & 97 \\
\hline & 170WPM & 6 & 96.3 & 4.2 & 90 & 92 & 99 & 99 & 100 \\
\hline & 260WPM & 6 & 92.5 & 5.8 & 85 & 88 & 93 & 98 & 98 \\
\hline \multirow{3}{*}{ Format } & Keyword & 9 & 95.8 & 3.2 & 90 & 93 & 97 & 98 & 100 \\
\hline & Phrase & 9 & 95.2 & 3.9 & 89 & 92 & 97 & 97 & 100 \\
\hline & Sentence & 9 & 94.4 & 5.2 & 85 & 91 & 96 & 98 & 100 \\
\hline \multirow{3}{*}{$\begin{array}{l}\text { Luminance } \\
\text { Contrast }\end{array}$} & $2 / 3$ & 9 & 95.6 & 3.2 & 89 & 93 & 97 & 97 & 99 \\
\hline & $4 / 5$ & 9 & 96.1 & 3.4 & 90 & 96 & 96 & 98 & 100 \\
\hline & $8 / 9$ & 9 & 93.8 & 5.4 & 85 & 90 & 96 & 97 & 100 \\
\hline
\end{tabular}

Table 2. Regression results based on model-selection for RCS

\begin{tabular}{lccccc}
\hline \multicolumn{1}{c}{ Model } & $\mathrm{R}^{2}$ & $\mathrm{R}_{\text {Adj }}$ & AIC & $\begin{array}{c}\text { Kolmogorov- } \\
\text { Smirnov }\end{array}$ & $\mathrm{P}$-value \\
\hline$(1) \mathrm{M}, \mathrm{P}, \mathrm{S}, \mathrm{M} \times \mathrm{P}, \mathrm{M} \times \mathrm{S}$ & 0.74 & 0.52 & 138.82 & 0.128 & $>0.150^{*}$ \\
$(2) \mathrm{M}, \mathrm{P}, \mathrm{S}, \mathrm{C}, \mathrm{M} \times \mathrm{P}, \mathrm{M} \times \mathrm{S}$ & 0.80 & 0.57 & 135.39 & 0.15 & $0.148^{*}$ \\
$(3) \mathrm{M}, \mathrm{P}, \mathrm{S}, \mathrm{C}, \mathrm{M} \times \mathrm{P}, \mathrm{M} \times \mathrm{S}, \mathrm{M} \times \mathrm{C}$ & 0.86 & 0.53 & 135.16 & 0.17 & $0.055^{*}$ \\
$(4) \mathrm{M}, \mathrm{P}, \mathrm{S}, \mathrm{F}, \mathrm{C}, \mathrm{M} \times \mathrm{P}, \mathrm{M} \times \mathrm{S}$ & 0.82 & 0.54 & 136.67 & 0.15 & $>0.150^{*}$ \\
$(5) \mathrm{M}, \mathrm{P}, \mathrm{S}, \mathrm{F}, \mathrm{C}, \mathrm{M} \times \mathrm{P}, \mathrm{M} \times \mathrm{S}, \mathrm{M} \times \mathrm{F}$ & 0.91 & 0.59 & 127.33 & 0.17 & 0.044 \\
\hline
\end{tabular}

Note: “*” indicates that Kolmogorov-Smirnov test doesn't violate normality at $\alpha=0.05$. 
Table 3. Analysis of parameter estimates for RCS

\begin{tabular}{|c|c|c|c|}
\hline Parameter & Estimate & $t$ & $P$-value \\
\hline Intercept & 89.96 & 6357.30 & $<.0001$ \\
\hline Leading & 0.33 & 0.04 & 0.8415 \\
\hline RSVP & 3.56 & 4.55 & $0.0329 *$ \\
\hline Bottom & 6.33 & 19.25 & $<.0001^{*}$ \\
\hline End-of-Search & 6.67 & 21.33 & $<.0001 *$ \\
\hline 170WPM & -3 & 4.32 & $0.0377 *$ \\
\hline 260WPM & -4.67 & 10.45 & $0.0012 *$ \\
\hline $2 / 3$ & 1.78 & 4.55 & $0.0329 *$ \\
\hline $4 / 5$ & 2.33 & 7.84 & $0.0051 *$ \\
\hline Leading $\times$ Bottom & -0.67 & 0.11 & 0.744 \\
\hline Leading×ESR & -1.33 & 0.43 & 0.5136 \\
\hline RSVP $\times$ Bottom & -1.33 & 0.43 & 0.5136 \\
\hline RSVP×ESR & -7.33 & 12.91 & $0.0003 *$ \\
\hline Leading $\times 170 \mathrm{WPM}$ & 7 & 11.76 & $0.0006^{*}$ \\
\hline Leading $\times 260 \mathrm{WPM}$ & 2.67 & 1.71 & 0.1914 \\
\hline
\end{tabular}

Note: $" * "$ denotes $t$ reaches statistical significance at $\alpha=0.05$.

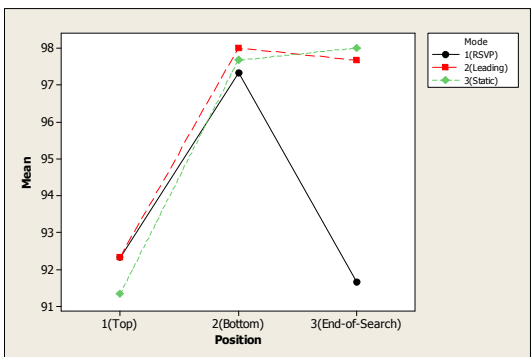

(a)

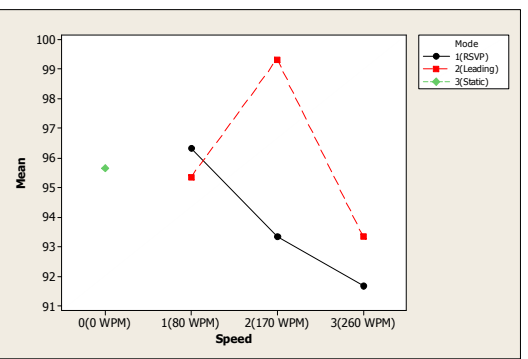

(b)

Fig. 1. Interaction plots: (a) presentation mode and position $(\mathrm{M} \times \mathrm{P})$, and (b) presentation mode and speed $(\mathrm{M} \times \mathrm{S})$ for $\mathrm{RCS}$

\subsection{User Interface Satisfaction (UIS)}

The quality of user experience is rated using the questionnaire of user interface satisfaction (UIS) based on the Likert's ten-point scale from 1 (extremely dislike) to 10 (extremely like). UIS score is the total of fifteen usability criteria rated after the experiment. Table 4 summarizes the fits of the five candidate models. Model (2) is ultimately chosen as the final model. The fitted regression model of UIS is expressed in Equation (2) as following:

$$
\begin{aligned}
& \hat{\mu}=118.67-60.22 \mathrm{M}_{1}-16.44 \mathrm{M}_{2}-10 \mathrm{P}_{1}+17 \mathrm{P}_{2}+4.5 \mathrm{~S}_{1}+11.17 \mathrm{~S}_{2}-6.67 \mathrm{~F}_{1}+4.67 \mathrm{~F}_{2} \\
& -3.67 \mathrm{C}_{1}+33.33 \mathrm{C}_{2}+11.67 \mathrm{M}_{1} \times \mathrm{P}_{1}+13.67 \mathrm{M}_{1} \times \mathrm{P}_{2}+11.67 \mathrm{M}_{2} \times \mathrm{P}_{1}+40.33 \mathrm{M}_{2} \times \mathrm{P}_{2} \\
& +51 \mathrm{M}_{1} \times \mathrm{F}_{1}+2 \mathrm{M}_{1} \times \mathrm{F}_{2}+0.67 \mathrm{M}_{2} \times \mathrm{F}_{1}-39.33 \mathrm{M}_{2} \times \mathrm{F}_{2} \\
& +7.67 \mathrm{M}_{1} \times \mathrm{C}_{1}+41.33 \mathrm{M}_{1} \times \mathrm{C}_{2}+25.67 \mathrm{M}_{2} \times \mathrm{C}_{1}+34.67 \mathrm{M}_{2} \times \mathrm{C}_{2}
\end{aligned}
$$


It indicates the interaction effects of presentation mode and position, presentation mode and format, as well as presentation mode and luminance contrast are statistically significant on user interface satisfaction.

Interaction plot of presentation mode and position $(\mathrm{M} \times \mathrm{P})$ is illustrated in Fig. 2(a). It indicates that the combination of Static $\times$ End-of-Search position has the highest UIS score; however, the combination of RSVP and End-of-Search position has the lowest UIS score. There is only little difference among Leading mode interacted with three positions. Interaction plot of presentation mode and format $(\mathrm{M} \times \mathrm{F})$ is illustrated in Fig. 2(b). It indicates the combination of Leading and Keyword format has the highest UIS score; however, the combination of Leading and Sentence format has the lowest UIS score. There are only little differences between RSVP and Static modes with Keyword and Sentence formats. The combinations of Static $\times$ Sentence and $\mathrm{RSVP} \times$ Sentence outperform than one of Leading $\times$ Sentence. In addition, the combination of Static $\times$ Phrase outperforms than the ones of Leading $\times$ Phrase and RSVP $\times$ Phrase. Interaction plot of presentation mode and luminance contrast $(\mathrm{M} \times \mathrm{C})$ is illustrated in Fig. 2(c). It indicates that the combinations of Staticxluminance contrast of 2/3 and Staticxluminance contrast of $8 / 9$ have the higher UIS out of other combinations. There is only little difference among the combinations of Leading, RSVP and Static modes interacted with luminance contrast of $4 / 5$.

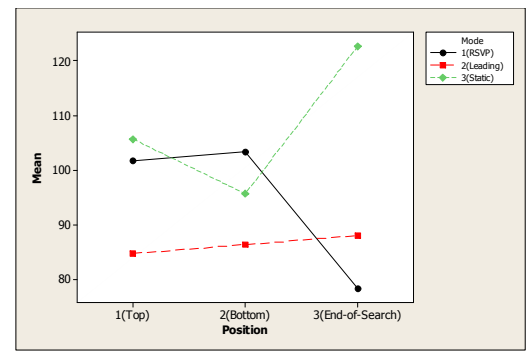

(a)

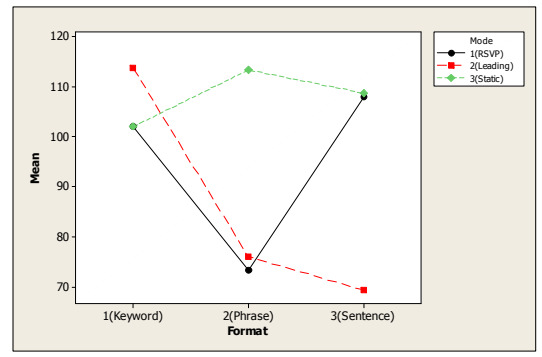

(b)

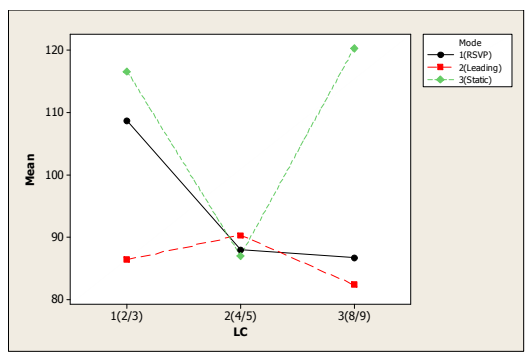

(c)

Fig. 2. Interaction plots: (a) presentation mode and position $(\mathrm{M} \times \mathrm{P})$, (b) presentation mode and format $(\mathrm{M} \times \mathrm{F})$, and $(\mathrm{c})$ presentation mode and luminance contrast $(\mathrm{M} \times \mathrm{C})$ for UIS 
Table 4. Regression results based on model-selection for UIS

\begin{tabular}{lccccc}
\hline \multicolumn{1}{c}{ Model } & $\mathrm{R}^{2}$ & $\mathrm{R}_{\text {Adj }}^{2}$ & $\mathrm{C}$ & $\begin{array}{c}\text { Kolmogorov- } \\
\text { Smirnov }\end{array}$ & P-value \\
\hline (1) $\mathrm{M}, \mathrm{P}, \mathrm{F}, \mathrm{C}, \mathrm{M} \times \mathrm{P}, \mathrm{M} \times \mathrm{F}, \mathrm{M} \times \mathrm{C}$ & 0.92 & 0.64 & 218.91 & 0.149 & $0.122^{*}$ \\
$(2) \mathrm{M}, \mathrm{P}, \mathrm{S}, \mathrm{F}, \mathrm{C}, \mathrm{M} \times \mathrm{P}, \mathrm{M} \times \mathrm{F}, \mathrm{M} \times \mathrm{C}$ & 0.94 & 0.63 & 212.59 & 0.135 & $>0.150^{*}$ \\
$(3) \mathrm{M}, \mathrm{F}, \mathrm{C}, \mathrm{M} \times \mathrm{F}, \mathrm{M} \times \mathrm{C}$ & 0.75 & 0.47 & 235.97 & 0.116 & $>0.150^{*}$ \\
$(4) \mathrm{M}, \mathrm{S}, \mathrm{F}, \mathrm{C}, \mathrm{M} \times \mathrm{F}, \mathrm{M} \times \mathrm{C}$ & 0.78 & 0.43 & 236.87 & 0.085 & $>0.150^{*}$ \\
$(5) \mathrm{M}, \mathrm{P}, \mathrm{F}, \mathrm{C}, \mathrm{M} \times \mathrm{P}, \mathrm{M} \times \mathrm{F}$ & 0.78 & 0.43 & 236.97 & 0.101 & $>0.150^{*}$ \\
\hline
\end{tabular}

Note: “*” indicates that Kolmogorov-Smirnov test doesn't violate normality at $\alpha=0.05$.

\subsection{Overall Workload}

NASA-TLX is used to evaluate task load including mental demand, physical demand, temporal demand, performance, effort, and frustration level for each task. The overall workload (OW) is defined as the weighted mean of importance for the pair wise comparison of six subscales. Summary statistics of overall workload is shown in Table 5. It indicates Static Mode has the lowest overall workload (mean of OW=29.3, $\mathrm{SD}=19.3$ ), Top position has the lowest overall workload (mean of $\mathrm{OW}=29.1$, $\mathrm{SD}=9.2$ ), Presentation speed of 80WPM has the lowest overall workload (mean of $\mathrm{OW}=30.4, \mathrm{SD}=16.2$ ), phrase-by-phrase format has the lowest overall workload (mean of $\mathrm{OW}=30.8, \mathrm{SD}=14.3$ ), and Luminance contrast of $4 / 5$ has the lowest overall workload (mean of $\mathrm{OW}=29.2, \mathrm{SD}=17.2$ ).

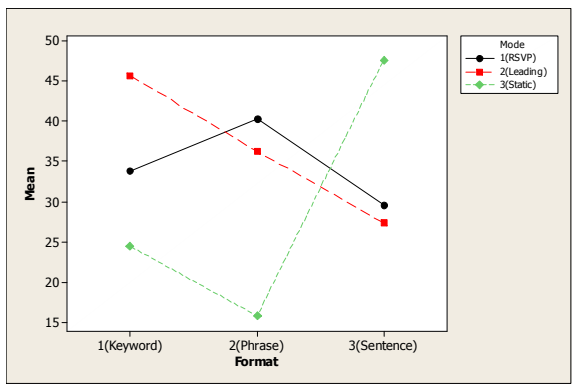

(a)

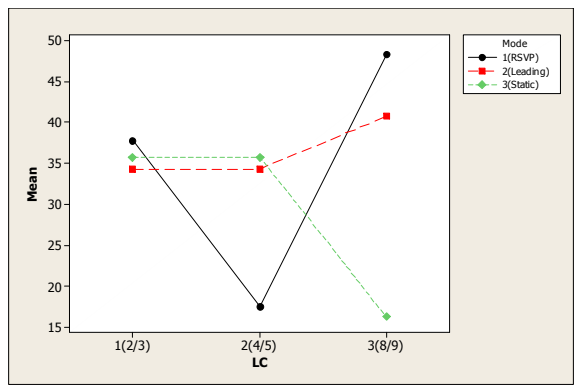

(b)

Fig. 3. Interaction plots: (a) presentation mode and format $(\mathrm{M} \times \mathrm{F})$, and (b) presentation mode and luminance contrast $(\mathrm{M} \times \mathrm{C})$ for $\mathrm{OW}$

Interaction plot of presentation mode and format is illustrated in Fig. 3(a). It indicates that the combination of Leading $\times$ Keyword results in higher workload than ones of Leading $\times$ Phrase and Leading $\times$ Sentence. There are only little differences between Leading and RSVP interacted with Sentence. The combination of Static $\times$ Phrase has the lowest overall workload in which it performs best among all combinations. Interaction plot of presentation mode and luminance contrast is illustrated in Fig. 3(b). There is only little difference among the combinations of Leading, RSVP and Static 
modes interacted with luminance contrast of $2 / 3$, however, Static mode interacted with luminance contrasts of $8 / 9$ and RSVP mode interacted with luminance contrasts of $4 / 5$ have lower workloads out of other combinations. In summary, there is the lowest overall workload for Static $\times$ Phrase and inverse, there is highest overall workload for Static $\times$ Sentence. In dynamic mobile ad displays, there are the lower overall workloads of Leading $\times$ Sentence and RSVP $\times$ Sentence than others. The speed of $80 \mathrm{WPM}$ is recommended for dynamic mobile ad displays.

\section{Conclusion}

Our experiment shows that the empirical study of the position of mobile text ad, moving speed, segmented format, and luminance contrast interacted with three presentation modes affecting significantly comprehension performance, user satisfaction, and overall workload. The main results obtained are the following: (1) interaction effects of presentation mode and position $(\mathrm{M} \times \mathrm{P})$, and presentation mode and speed $(\mathrm{M} \times \mathrm{S})$ are important on comprehension performance, (2) interaction effects of presentation mode and position $(\mathrm{M} \times \mathrm{P})$, presentation mode and format $(\mathrm{M} \times \mathrm{F})$, and presentation mode and luminance contrast $(\mathrm{M} \times \mathrm{C})$ are important on user interface satisfaction, (3) interaction effects of presentation mode and format $(\mathrm{M} \times \mathrm{F})$, and presentation mode and luminance contrast $(\mathrm{M} \times \mathrm{C})$ are also important on overall workload. The condition of Static mode and End-of-Search position plays an important role on comprehension performance and has the consistently highest user satisfaction. However, the condition of RSVP and End-of-Search position performs the worst comprehension performance and has the lowest user satisfaction. In summary, the interaction effects between text advertising visual structures have to be taken into account for the usercentered usability of mobile text advertising presentation.

Table 5. Summary statistics of overall workload (OW)

\begin{tabular}{|c|c|c|c|c|c|c|c|c|c|}
\hline Factor & Level & $\mathrm{n}$ & Mean & SD & Min & $\mathbf{Q}_{1}$ & $\mathbf{Q}_{2}$ & $\mathbf{Q}_{3}$ & Max \\
\hline \multirow{3}{*}{ Mode } & RSVP & 9 & 34.6 & 18.2 & 7.4 & 20 & 39.3 & 42.2 & 65.2 \\
\hline & Leading & 9 & 36.5 & 11.7 & 20.7 & 23.7 & 38.5 & 45.2 & 51.1 \\
\hline & Static & 9 & 29.3 & 19.3 & 9.6 & 16.3 & 23.0 & 37.8 & 64.4 \\
\hline \multirow{3}{*}{ Position } & Top & 9 & 29.1 & 9.2 & 17.0 & 20.7 & 28.9 & 37.8 & 40.7 \\
\hline & Bottom & 9 & 36.8 & 14.2 & 16.3 & 25.9 & 40.7 & 45.2 & 55.6 \\
\hline & End-of-Search & 9 & 34.4 & 23.5 & 7.4 & 14.1 & 23.7 & 51.1 & 65.2 \\
\hline \multirow{3}{*}{ Speed } & 80WPM & 6 & 30.4 & 16.2 & 7.4 & 20.0 & 31.9 & 40.7 & 50.4 \\
\hline & 170WPM & 6 & 43.5 & 13.0 & 28.9 & 34.8 & 40.4 & 51.1 & 65.2 \\
\hline & 260WPM & 6 & 32.7 & 14.4 & 16.3 & 20.7 & 31.5 & 45.2 & 51.1 \\
\hline \multirow{3}{*}{ Format } & Keyword & 9 & 34.7 & 18.1 & 9.6 & 20.0 & 37.8 & 45.2 & 65.2 \\
\hline & Phrase & 9 & 30.8 & 14.3 & 14.1 & 17.0 & 28.9 & 40.7 & 51.1 \\
\hline & Sentence & 9 & 34.9 & 18.1 & 7.4 & 23.0 & 38.5 & 42.2 & 64.4 \\
\hline \multirow{3}{*}{$\begin{array}{l}\text { Luminance } \\
\text { Contrast }\end{array}$} & $2 / 3$ & 9 & 36.0 & 14.0 & 14.1 & 23.7 & 38.5 & 42.2 & 55.6 \\
\hline & $4 / 5$ & 9 & 29.2 & 17.2 & 7.4 & 17.0 & 25.9 & 34.8 & 64.4 \\
\hline & $8 / 9$ & 9 & 35.1 & 18.7 & 9.6 & 20.7 & 39.3 & 50.4 & 65.2 \\
\hline
\end{tabular}




\section{References}

1. Hart, S.G., Staveland, L.E.: Development of NASA-TLX (Task Load Index): Results of Empirical and Theoretical Research. In: Hancock, P.A., Meshkati, N. (eds.) Human Mental Workload, pp. 239-250 (1988)

2. Interactive Ad Bureau, A Mobile Advertising Overview, pp. 4-6 (2008), http: / / www. iab. net

3. Interactive Ad Bureau, IAB Internet Ad Revenue Report, pp. 8-10 (2008), http: / / www. iab. net

4. Juola, J.F., Tiritoglu, A., Pleunis, J.: Reading Text Presented on a Small Display. Applied Ergonomics 26(3), 227-229 (1995)

5. Juola, J.F., Ward, N.J., McNamara, T.: Visual Search and Reading of Rapid Serial Presentations of Letter Strings, Words and Text. J. Exper. Psychol:General 111, 208-227 (1982)

6. Laarni, J.: Search for Optimal Methods of Presenting Dynamic Text on Different Types of Screens. In: ACM International Conference Proceeding Series, vol. 31, pp. 219-222 (2002)

7. Lin, Y.L., Chen, Y.W.: Effects of Ad Type, Position, Animation Length, and Exposure Times on Click-Through Rate of Online Advertisings. Computers \& Industrial Engineering 57(2), 580-591 (2009)

8. Mobile Marketing Association, Mobile Advertising Guidelines, pp. 3-10 (2008), https: / /mmaglobal.com/

9. Muter, P.: Interface design and optimization of reading of continuous text. Cognitive Aspects of Electronic Text Processing, 161-180 (1996)

10. Wang, A.H., Fang, J.J., Chen, C.H.: Effects of VDT Leading-Display Design on Visual Performance of Users in Handling Static and Dynamic Display Information Dual-tasks. International Journal of Industrial Ergonomics 32, 93-104 (2003) 